\title{
Environmental Factors Are Stronger Predictors of Primate Species' Distributions Than Basic Biological Traits
}

\section{Katherine A. Williams, et al. [full author details at the end of the article]}

Received: 6 August 2020 / Accepted: 5 February 2021/ Published online: 23 April 2021

(C) The Author(s) 2021, corrected publication 2021

\begin{abstract}
Understanding the neutral, biological, and environmental processes driving species distributions is valuable in informing conservation efforts because it will help us predict how species will respond to changes in environmental conditions. Environmental processes affect species differently according to their biological traits, which determine how they interact with their environment. Therefore, functional, trait-based modeling approaches are considered important for predicting distributions and species responses to change but even for data-rich primate communities our understanding of the relationships between traits and environmental conditions is limited. Here we use a large-scale, high-resolution data set of African diurnal primate distributions, biological traits, and environmental conditions to investigate the role of biological traits and environmental trait filtering in primate distributions. We collected data from published sources for 354 sites and 14 genera with 57 species across sub-Saharan Africa. We then combined a three-table ordination method, RLQ, with the fourth-corner approach to test relationships between environmental variables and biological traits and used a mapping approach to visually assess patterning in primate genus and species' distributions. We found no significant relationships between any groups of environmental variables and biological traits, despite a clear role of environmental filtering in driving genus and species' distributions. The most important environmental driver of species distributions was temperature seasonality, followed by rainfall. We conclude that the relative flexibility of many primate genera means that not any one particular set of traits drives their species-environment associations, despite the clear role of such associations in their distribution patterns.
\end{abstract}

Keywords Africa $\cdot$ Climate $\cdot$ Environmental trait filtering $\cdot$ Fourth corner $\cdot$ Functional diversity $\cdot$ Primate assemblages $\cdot$ RLQ

Handling Editor: Joanna Setchell. 


\section{Introduction}

Human-driven pressures such as habitat loss, fragmentation, and climate change are increasingly influencing animals' populations and geographical ranges. Because they are found in the tropics, primates are predicted to experience a greater climate changerelated temperature shift than the global mean, highlighting the importance of understanding their potential response to environmental change (Graham et al. 2016; Korstjens and Hillyer 2016; Stewart et al. 2020). Accurately modeling these responses can help predict the most effective locations for future protected areas and identify species that are most at risk, greatly aiding conservation efforts (Connolly et al. 2017). Current species distribution models generally incorporate climatic variables and species' presence data but usually do not account for functional traits (Wittmann et al. 2016), which influence how different species interact with their environment. While correlative distribution models can be used to make some broad predictions about potential animal range changes, they cannot provide detailed information about individual species' responses to environmental change, as they lack a mechanistic element. Understanding the underlying mechanisms that drive distributions, related to how animals interact with their environment, will help to improve the predictive power of species distribution models by allowing mechanistic methods to be applied where enough data are available (Connolly et al. 2017; Dunbar et al. 2009).

Species distributions and resulting community structure are thought to be shaped by three main mechanisms: neutral processes, abiotic filtering (environmental processes), and biotic filtering (interspecific interactions) (Bannar-Martin 2014; Pavoine et al. 2011). Although distribution is most likely driven by a combination of all three, they are often studied independently (Gouveia et al. 2014). Models based on neutral processes are perhaps the simplest, since they assume that all organisms in the same trophic level are competitively equivalent and distribution patterns are driven mostly by dispersal limitations (Rosindell et al. 2011). Neutral processes are important in driving community assembly in primates (Bannar-Martin 2014; Beaudrot and Marshall 2011). Current and historical environmental conditions are also important drivers of primate community structure and distributions, although the relative importance of specific climatic variables varies between regions and species (Beaudrot and Marshall 2019; Korstjens et al. 2018; Rowan et al. 2016, 2020). For example rainfall explains community structure in African, Malagasy, and American primate communities and maximum temperature in American communities (Kamilar 2009). Less work has been done on the role of biotic filtering on primate communities and distributions, though competition within arboreal guenon (genera Cercopithecus and Allochrocebus) multispecies communities limit individual species' distributions (Korstjens et al. 2018). Different species have different ecological requirements and adaptations (Hidasi-Neto et al. 2012; Laughlin et al. 2011), leading to different fitness in different locations, depending on environment, competitors, predators, and pathogens (Pavoine et al. 2011; Ricklefs 2015). The biological traits that drive primate distributions most strongly, are, however, still unclear.

To better predict species' responses to environmental change, we need to understand not just the role of environmental filtering on species' distributions but also the mechanisms behind species-environment relationships. Recent work has investigated environmental filtering by focusing on phylogenetic structuring within communities 
(Kamilar et al. 2014; Mazel et al. 2015). Phylogeny is often assumed to be closely related to ecological similarity, as biological traits tend to be conserved among closely related species (Kamilar et al. 2015). It is hypothesized that closely related species exploit similar ecological niches and will be found in similar habitats, leading to phylogenetically clustered communities (Kamilar et al. 2015). If this is the case, then environment is likely an important driver of community composition. However, an alternative hypothesis suggests that competitive exclusion can cause closely related species to be overdispersed rather than clustered (Kamilar et al. 2015). If this is the case, environmental filtering is less important than neutral and biotic processes, though these factors are not entirely independent of each other (Cadotte and Tucker 2017).

Communities of birds and African mammals show significant phylogenetic structuring that can be linked to environmental conditions (Cardillo 2011; Hidasi-Neto et al. 2012). For primate communities, however, some studies show little or no phylogenetic structuring (Hidasi-Neto et al. 2012; Kamilar et al. 2015), suggesting that null processes such as dispersal limitation play a greater role than environmental filtering (Beaudrot and Marshall 2011). Other studies find a stronger effect of environmental filtering on community similarities, with the effects being stronger for genus-level than species-level analyses (Beaudrot and Marshall 2019). Likewise, ecologically similar primate species have been found to cluster according to ecoregion (Fleagle and Reed 1996; Muldoon and Goodman 2010), suggesting a role for environment in community assembly. In addition, primate species richness can be mapped according to environmental variables (Gaston 2000), so the total number of species in a community appears to be driven by environment. In primates, the most important environmental factors shown to drive species richness are rainfall, forest productivity, and forest structure (Gouveia et al. 2014; Kay et al. 1997; Wang et al. 2013), as well as historical biogeographical factors (Kay et al. 1997). However, whether environmental variables influence the species that make up a community rather than just the total number of species an environment can support requires further study.

A significant limitation of using phylogenetic structure to indicate similarity in biological traits is that, although traits are often conserved among closely related species, there can be significant convergence among species that are not closely related, and divergence in species that are closely related (Losos 2008). In addition, there is growing evidence that phylogenetic relationships poorly explain the outcome of competition between ecologically similar species, which may be more complex than is often assumed (Mayfield and Levine 2010; Ricklefs 2015). Therefore, phylogenetic community structure may not always provide an accurate picture of how speciesenvironment relationships drive species communities and species distribution patterns. Even without these issues, while phylogenetic structuring can indicate whether environment-trait relationships influence community structure, it cannot identify which particular environmental or biological traits are important; for this a trait-based approach is required.

Trait-based approaches allow species-independent observations, which are broadly applicable even when data for individual species are limited (Santini et al. 2016), and can be used to create predictive models of how distributions respond to environmental change (Wittmann et al. 2016). Biological traits influence how an organism interacts with its environment and define the niche of that organism. Understanding functional links between environment, traits, and distribution could enable the development of 
mechanistic predictive models of how changing environments will affect different organisms (Laughlin et al. 2011), and identify species that may be at risk of extinction (Davidson et al. 2017). Species traits have been linked with environmental conditions in birds, butterflies, and forest plants (Hanspach et al. 2015; Laughlin et al. 2011; Wittmann et al. 2016), and in small mammals the most abundant species at particular locations share similar traits (Hidasi-Neto et al. 2020). A small number of studies have looked at the role of traits in defining primate distributions (Fleagle and Reed 1996; Muldoon and Goodman 2010; Razafindratsima et al. 2012). A recent study incorporated traits into an analysis of primate species' susceptibility to extreme weather, in which they predetermined the traits they considered important in defining extreme event vulnerability (Zhang et al. 2019). To predict how species may respond to environmental changes, however, we need to independently identify which traits are associated with which environmental conditions.

We use a trait-based statistical approach to test the role of environmental filtering in driving primate distributions. We investigate associations between climate, canopy height, and functional traits across 57 species from 14 primate genera in 354 sites across sub-Saharan Africa. We use a three-table ordination approach using a combination of RLQ ordination and fourth-corner analyses to identify associations between environment and biological traits. Unlike more traditional ecological approaches, this provides a mechanistic link between organism and environment that could then be applied to develop predictive models: if particular traits are linked with particular environmental conditions then species with those traits should be affected if the relevant environmental condition alters. This type of large-scale study has been made possible only relatively recently by the increasing availability of high-quality global data sets for both climate and species distributions (Kamilar and Beaudrot 2013).

Our overall hypothesis is that a primate's ability to survive in a particular location is affected by how well suited its biological traits are to the environmental conditions in that area. If this is the case then specific biological traits (Table I) will be associated with specific environmental variables (Fig. 1 and Electronic Supplementary Material 1 [ESM 1] Table SI).

\section{Methods}

\section{Data Sets}

We carried out analyses at both genus and species level on haplorrhine primates because genus- and species-level patterns may differ (Beaudrot and Marshall 2019). We excluded strepsirrhines (Fleagle and Reed 1996), as they occupy a significantly different area of niche space to other primates, being nocturnal or restricted to Madagascar (the lemurs). In addition, a lack of presence/absence data for strepsirrhines on the African continent means that including strepsirrhines in the analysis would severely reduce the number of sites we could include.

We collated presence and absence of 57 species from 14 haplorrhine genera following the taxonomy from Kingdon et al. (2013) across sub-Saharan Africa for sites where at least one haplorrhine species occurred (Korstjens et al. 2018; ESM 2). We included the species Allochrocebus lhoesti, A. preussi, and A. solatus (Kingdon and 
Environmental variables

Biological traits

Intermediate effects not directly included in analysis

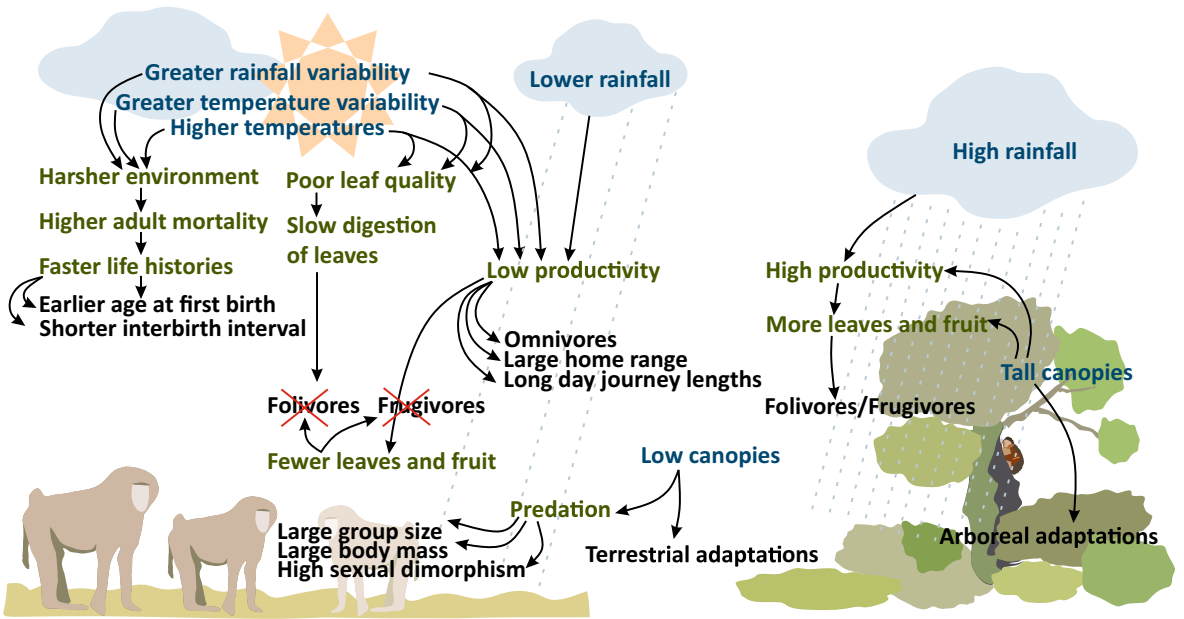

Fig. 1 Predicted relationships between environmental variables and biological traits in primates, based on current literature. Environmental variables and biological traits are aspects of the inputs we chose for the RLQ model in this study, while intermediate effects are included to detail the reasoning behind the predictions.

Groves 2013) within the genus Cercopithecus because some analyses show they can be considered very closely related or of the same genus (Guschanski et al. 2013). We used the United Nations Environmental Programme (UNEP) World Conservation Monitoring Centre (WCMC) database on protected areas (accessed between 2003 and 2006) and the African Protected Areas Assessment Tool (APAAT; Hartley et al. 2007), accessed in 2013-2014, to locate potential sites. The WCMC and APAAT data are now part of the Digital Observatory for Protected Areas (DOPA; https://dopa.jrc.ec.europa.eu/en/mapsanddatasets). We used Google and Google Scholar to locate reports and scientific publications about primate presence at those locations using the site's name to verify or complete the data available in the WCMC and APAAT database. If this search produced country- or region-wide primate surveys that included further locations, we also included those in the data set. We then projected the locations of sites onto a map of Africa to identify geographical gaps in distribution information and conducted an intensive search to fill those gaps, using the keywords: country name with census, primates, mammals, Cercopithecus, Colobus, ape or monkey. This identified additional sites that did not have the protection status of those appearing on UNEP databases, giving a total of 354 sites (Fig. 2). Information on species' presence represents the situation since 1970, which means that in a few cases the populations may have since gone extinct. We verified or completed conflicting or incomplete information by searching for additional reliable scientific reports and publications. Although it is common practice to use species range map data as a proxy for presence/absence or for developing niche models of the climatic range (Gouveia et al. 2014), these tend to overestimate presence (Hurlbert and Jetz 2007) and niche breadth. Therefore, although a smaller overall area is covered using site specific presence/absence data, it is likely to be more accurate than total coverage alone.

We compiled high-resolution bioclimate data (at 30-s intervals) from WorldClim's global climate database version 1.4 following (Hijmans et al. 2015). 


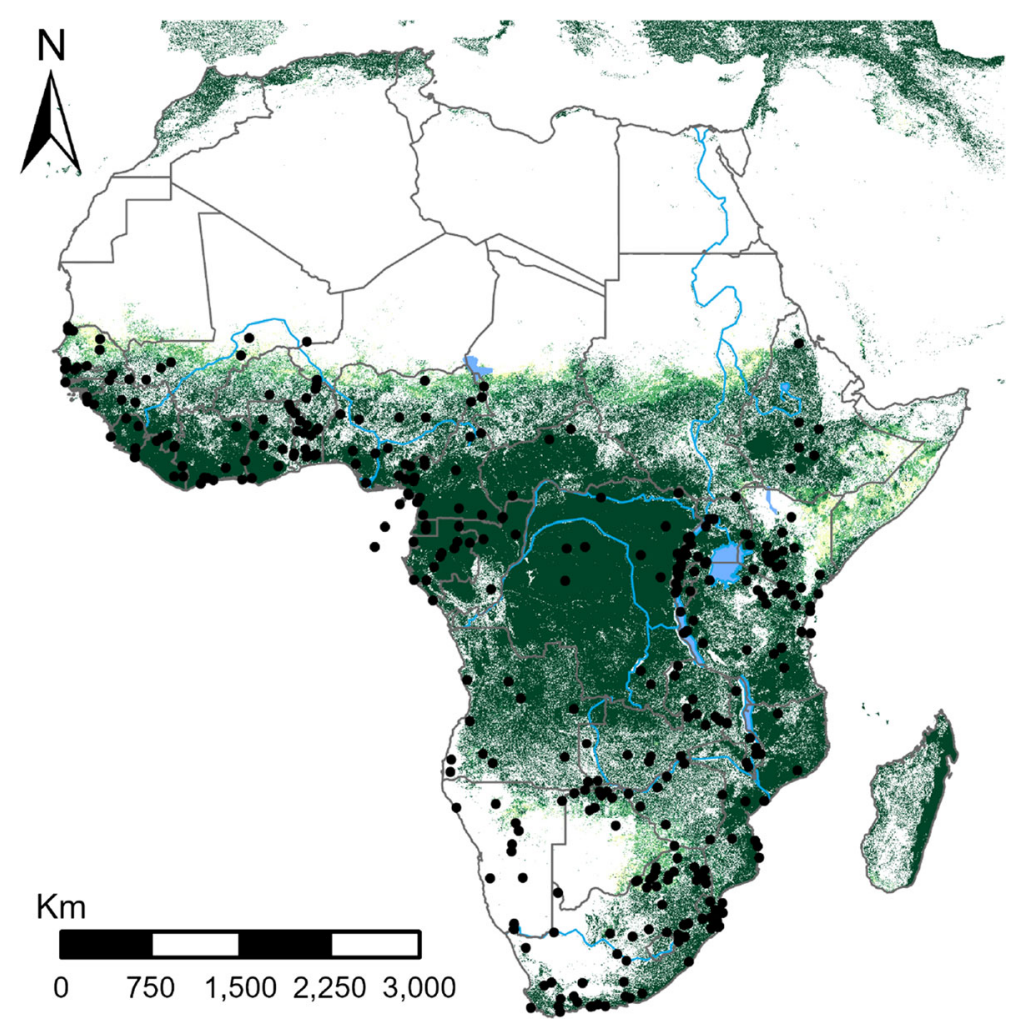

Fig. 2 Map of Africa showing sites used in analyses of relationships between environmental variables and biological traits in African haplorrhines. Intensity of green indicates canopy height, based on the global canopy height database of Simard et al. (2011) at $1 \mathrm{~km}$ resolution.

We used the climate variables mean annual temperature (BIO1); diurnal temperature range (BIO2; mean of monthly max temperature - min temperature); temperature seasonality (BIO4; standard deviation of monthly mean temperatures $\times 100$ ); mean annual precipitation (BIO12); and precipitation seasonality (BIO15; coefficient of variation of monthly rainfall). These variables were shown to be important in previous primate studies (Dunbar et al. 2009; Gouveia et al. 2014; Korstjens 2019; Wang et al. 2013). We used canopy height as a proxy for forest stratification (Gouveia et al. 2014) and extracted high-resolution (1 km) canopy height data from the global canopy height database Simard et al. (2011). For each site, we used the latitude/longitude values (reflecting the center of a park if the location referred to a protected area) to extract a single data point for each climate measure in R3.1.1 ( $\mathrm{R}$ Core Team 2016) using the RStudio Version 0.99.903 for Windows interface.

We compiled trait data from published sources (Table I; ESM 2). Where speciesspecific trait data were unavailable, we used a genus median; this occurred mainly in traits such as age at first birth and intermembral index where more limited data are available (ESM 1 Table SIIa). We calculated genus values as the median of all species for which data were available (ESM 2). All quantitative trait variables showed a skewed distribution, so we log transformed them prior to any further statistical analysis. 
Table I Summary table of biological traits included in analyses of relationships between environmental variables and biological traits in African haplorrhines

\begin{tabular}{|c|c|c|}
\hline Trait code & Details/categories & References \\
\hline IMI & $\begin{array}{l}\text { Intermembral index } \\
\text { (Length of the humerus }+ \text { Length of the radius }) \times 100 / \\
\text { (Length of the femur + Length of the tibia) }\end{array}$ & $\begin{array}{l}\text { Jungers 1985; } \\
\quad \text { Richmond et al. } 2002\end{array}$ \\
\hline Body mass & $\log ^{10}$ mean of male and female body mass $(\mathrm{kg})$ & Smith and Jungers 1997 \\
\hline Sexual dimorphism & Ratio of female/male mean body mass & Smith and Jungers 1997 \\
\hline Diet & Omnivore; leaf; fruit & $\begin{array}{l}\text { Isbell and Van Vuren 1995; } \\
\text { Kingdon et al. 2013; } \\
\text { Lahm } 1986\end{array}$ \\
\hline Group size & Mean group size & $\begin{array}{l}\text { Abernethy et al. 2002; } \\
\text { Willems et al. } 2013\end{array}$ \\
\hline Substrate & Arboreal or terrestrial & $\begin{array}{l}\text { Campbell et al. 2007; } \\
\quad \text { Kingdon et al. } 2013\end{array}$ \\
\hline IBI & Interbirth interval (days) & $\begin{array}{l}\text { Campbell et al. } 2007 ; \\
\quad \text { Kingdon et al. } 2013\end{array}$ \\
\hline Home range & Mean size of home range (ha) & $\begin{array}{l}\text { Campbell et al. } 2007 ; \\
\text { Kingdon et al. } 2013\end{array}$ \\
\hline Daily travel & Mean daily travel distance $(\mathrm{m})$ & $\begin{array}{l}\text { Campbell et al. } 2007 ; \\
\text { Kingdon et al. } 2013\end{array}$ \\
\hline
\end{tabular}

We included species that were identified as semiterrestrial in our "terrestrial" group because almost all terrestrial primates use trees regularly and could be considered semiterrestrial. Omnivore includes all species identified as omnivore or fruit-omnivore. We considered all colobines as folivores.

\section{Statistical Analysis}

We performed RLQ and fourth-corner analyses in R version 3.1.1 using the ade4 package (Dray and Dufour 2007; code in ESM 1). RLQ analysis involves building three data matrices: an R matrix for sites and environmental variables, an L matrix for sites and species occurrence data, and a Q matrix for species and biological traits. First, we performed a correspondence analysis on the species' presence/absence matrix L, then, a principal component analysis on the environment matrix $\mathrm{R}$ (all data are numeric), and a Hill-Smith test on the traits matrix Q (to allow for both numeric and categorical data). The subsequent RLQ analysis combines the results of these analyses to look for correlations between the environment gradients and trait syndromes, giving a measure of association (corr L; Dray et al. 2014). CorrL identifies how well each axis emerging from the RLQ analysis explains the variation found in the species distribution matrix (L). We used Monte Carlo permutation tests with 4999 permutations to test whether this association was statistically significant $(P<0.05)$. We used three different permutation models, each of which holds different elements fixed in order to test associations between the others (Dray et al. 2014). First, we permuted the rows of species presence $(\mathrm{L})$ or environment $(\mathrm{R})$ to test the null hypothesis that the distribution 
of species with fixed traits $(\mathrm{Q})$ is not influenced by environment. Second, we permuted the species presence (L) to test the null hypothesis that the species' composition of samples with fixed environmental conditions (R) is not influenced by species trait (Q). Finally, we combined the first two models to test the null hypothesis that at least one of $\mathrm{R}$ and $\mathrm{Q}$ is not linked to $\mathrm{L}$ (occurence), against the alternative hypothesis that both traits and environment affect species' distributions.

We used the fourth-corner method to look for specific environment-trait relationships, without the added complexity of multivariate analyses. We corrected the $P$-values using the False Discovery Rate (FDR) procedure due to multiple comparisons (Dray et al. 2014). Finally, we used a hierarchical cluster analysis to separate genera and species into functional groups based on their trait scores from the RLQ analysis. We mapped these groups in Q-GIS Desktop 2.8.2, using the reference system WGS84, to show distributions of these functional groups. There is intercorrelation among the environmental variables and among the species traits (ESM 1 Tables IIb-d), but this is not an issue for this particular analysis because the analysis incorporates a factor analysis that combines biological traits and environmental conditions each into two main component axes. There will be some spatial autocorrelation among the site data, despite our every effort to find sites across Africa. Although the analyses are relatively robust against spatial autocorrelation (4999 permutations are run), we also reran the full analyses on a reduced data set of 177 sites that were all separated at least 1 degree longitude and latitude in all directions from each other (ESM 1). This more conservative analysis did not give us substantially different results so we used the full data set in this study.

\section{Ethical Note}

This study did not include any direct research on animal or human subjects. The authors declare that they have no conflicts of interest.

Data Availability Species trait and environmental data used in this project are presented in the supplementary materials (ESM 2) and they are available on BORDAR, Bournemouth University's open access database (https://doi.org/10. 18746/bmth.data.00000142). Access to the datafile containing species presence/ absence per site can be made available on reasonable request to the corresponding author.

\section{Results}

\section{Genus Level RLQ, Fourth-Corner, and Monte Carlo Analyses}

The first two RLQ ordination axes account for $97.78 \%$ of total inertia in species distribution patterns, with the first axis accounting for most of this $(95.31 \%$; Table II). The first axis is well correlated with the site-by-species matrix (correlation with L, Table II). Interbirth interval, age at first birth (together explaining $34.48 \%$ of 
Table II Summary of RLQ results testing relationships between environmental variables and biological traits at genus level in African haplorrhines

\begin{tabular}{lllll}
$\begin{array}{l}\text { RLQ } \\
\text { axis }\end{array}$ & Eigenvalues & Covariance & $\begin{array}{c}\text { Contribution to } \\
\text { total inertia }(\%)\end{array}$ & $\begin{array}{l}\text { corrL (correlation between trait-based species scores } \\
\text { and site-based environmental scores) }\end{array}$ \\
\hline 1 & 1.72 & 1.31 & 95.31 & 0.48 \\
2 & 0.04 & 0.21 & 2.47 & 0.13 \\
\hline
\end{tabular}

inertia), substrate use (total 16.87\%), and diet (total 18.67\%) are the most important contributors to the inertia for the relationship between trait and distributions (matrices $\mathrm{Q}$ and L) (Table III). The most important environmental variables are temperature seasonality, annual precipitation, and canopy height (Table III). Primate genera that are terrestrial and omnivorous are associated with higher temperature seasonality, diurnal range, and precipitation seasonality, while genera that are arboreal and frugivorous or folivorous are associated with higher precipitation and increased canopy height (Figs. 3a, b and 4). There were no significant relationships between the RLQ axes of the environmental matrix (R) and individual biological traits (Fig. 3c). The first

Table III Percentage contributions to total inertia and relative contributions (\%) to both RLQ axes of individual biological trait and environmental variables in analyses testing relationships between environmental variables and biological traits in African haplorrhine genera

\begin{tabular}{llll}
\hline Variable & Inertia $(\%)$ & Axis 1 (\%) & Axis 2 (\%) \\
\hline Biological trait variables & & & \\
Arboreal & 10.34 & 10.72 & 2.08 \\
Terrestrial & 6.53 & 6.77 & 1.31 \\
Frugivorous & 6.69 & 6.01 & 0.33 \\
Omnivorous & 4.33 & 4.45 & 0.99 \\
Folivorous & 7.65 & 7.84 & 4.66 \\
Intermembral index & 0.52 & 0.27 & 5.01 \\
Body mass & 2.06 & 1.82 & 7.96 \\
Group size & 4.36 & 3.57 & 34.25 \\
Age at first birth & 14.93 & 15.16 & 19.09 \\
Sexual dimorphism & 7.88 & 8.02 & 0.96 \\
Interbirth interval & 19.55 & 20.04 & 16.99 \\
Home range size & 1.12 & 0.73 & 0.52 \\
Daily travel & 14.07 & 14.59 & 5.84 \\
Environmental variables & & & \\
Mean annual temperature & 1.96 & 0.76 & 16.32 \\
Temperature diurnal range & 16.01 & 16.58 & 1.35 \\
Temperature seasonality & 29.02 & 29.13 & 42.44 \\
Annual precipitation & 21.85 & 22.51 & 5.68 \\
Precipitation seasonality & 12.09 & 11.97 & 7.84 \\
Canopy height & 19.06 & 19.05 & 26.37 \\
\hline & & & \\
\hline
\end{tabular}




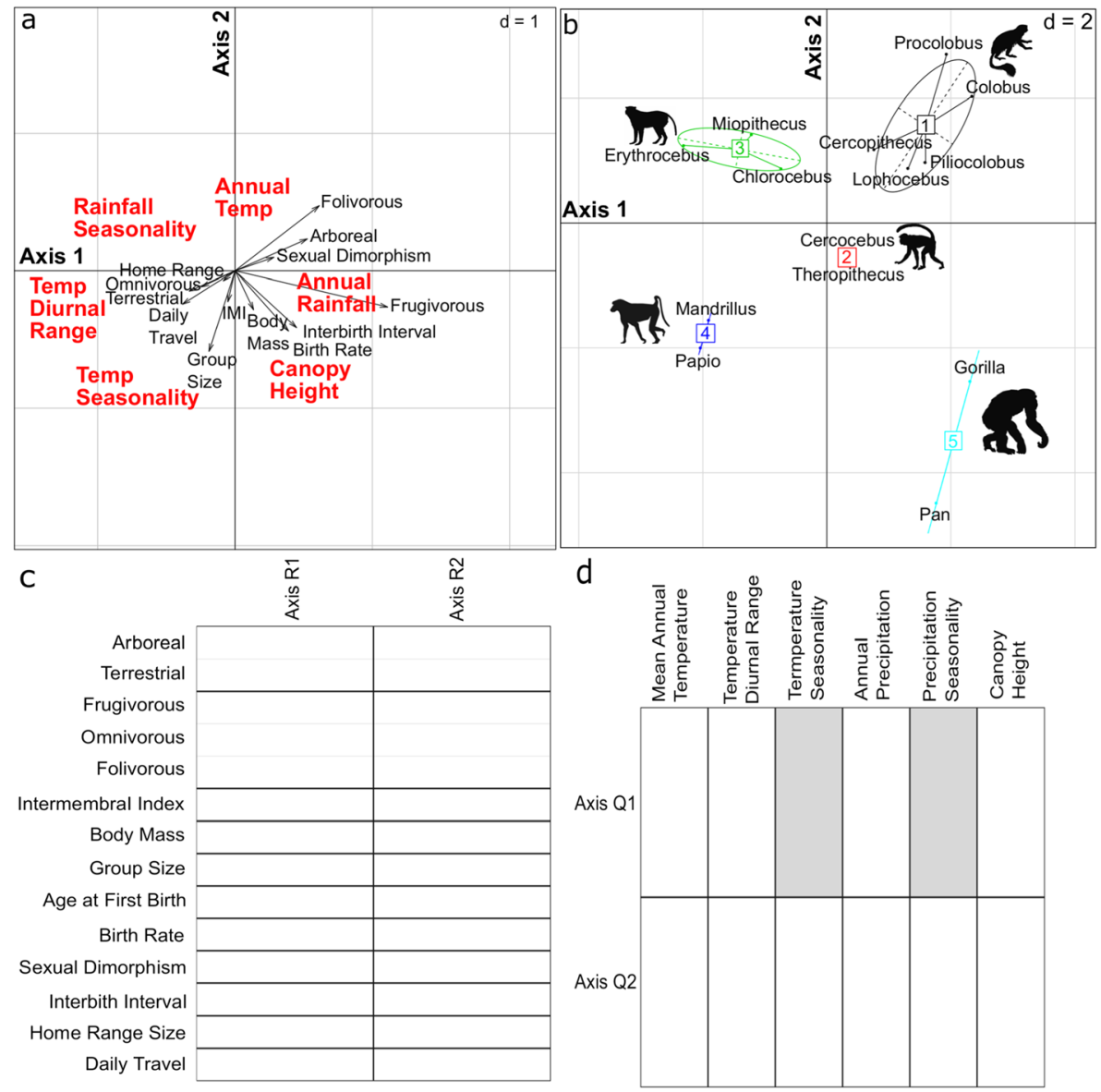

Fig. 3 Results of RLQ and fourth-corner analyses testing relationships between environmental variables and biological traits at genus level in African haplorrhines. a Coefficients for biological traits and environmental variables for RLQ analysis. b Scores for genera in RLQ analysis. Colored ellipses indicate clusters of ecologically similar genera identified in the analysis as shown in Fig. 4 and ESM 1 Table SIII. c Fourthcorner tests of association between the first two RLQ axes for environmental gradients (AxisR1 and AxisR2) and individual biological trait variables. d Fourth-corner tests of associations between the first two RLQ axes for trait gradients (Axis Q1 and Axis Q2) and individual environmental variables. In $\mathbf{c}$ and $\mathbf{d}$, light gray cells represent significant negative associations, and white cells represent no significant association (there were no significant positive associations).

RLQ ordination axis of the traits matrix (Q) was negatively associated with precipitation seasonality and temperature seasonality (Fig. 3d).

Fourth-corner tests indicate significant negative associations between precipitation seasonality and interbirth interval when $\alpha=0.05$. However, when we adjust $\alpha$ to account for multiple comparisons, there are no significant correlations between the environment and genus traits (ESM 1 Table SIII). Combining the fourth-corner and RLQ analyses with Monte Carlo tests confirms that only the first model is significant, where we permuted the rows of species presence $(\mathrm{L})$ or environment $(\mathrm{R})$ to test the null hypothesis that the distribution of species with fixed traits (Q) is not influenced by environment, implying that environment was important in determining species' 


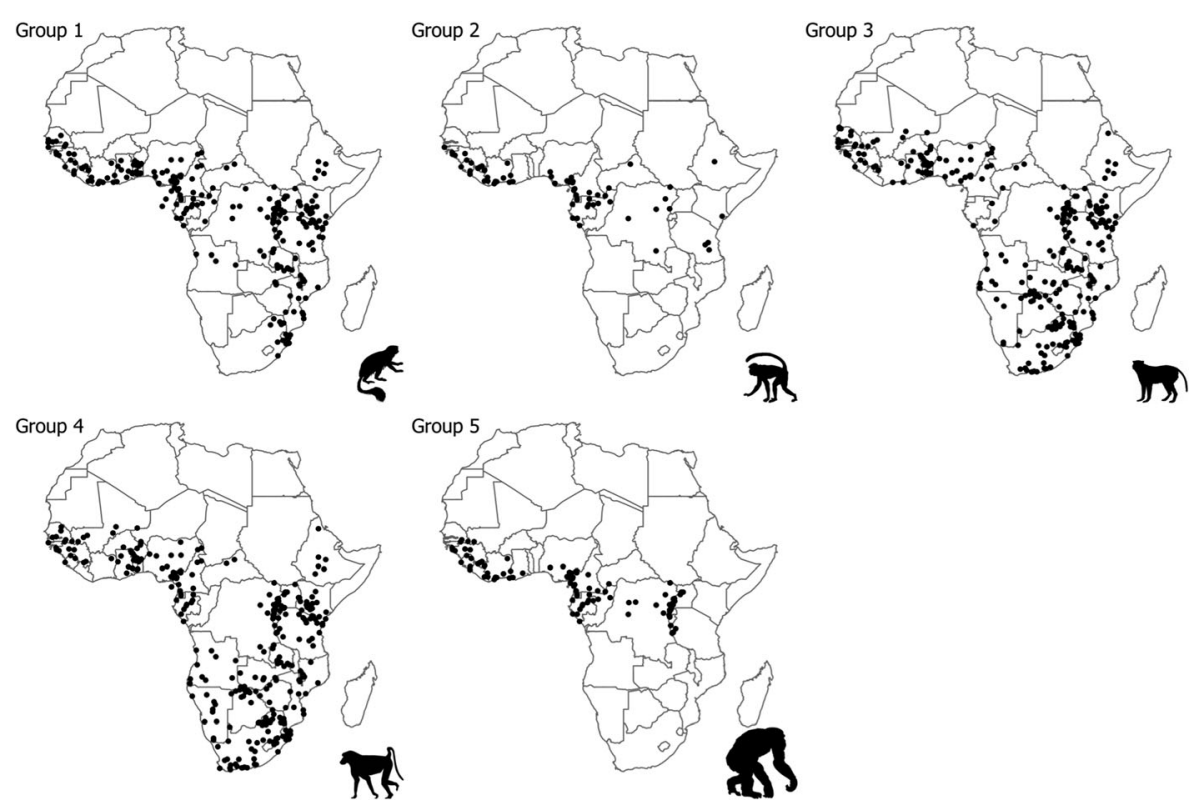

Fig. 4 Maps to show distributions (location where they are present) of each ecologically similar genus group based on trait scores in an analysis of relationships between environmental variables and biological traits in African haplorrhines (group membership is given in ESM 1 Table SIV).

distributions, while traits were not (Table IV). Associations between distributions and genus traits were not significant; most of the variation in distributions therefore was explained by environmental factors.

Differences Between Genus Groups

We placed genera into functional groups based on their trait scores from the RLQ analysis (Figs. 3a and 4, and ESM 1 Fig. S1 and Table SIV). For most traits, functional groups did not differ significantly, although group 5 (genera Gorilla and Pan) had a higher body mass, interbirth interval, and age at first birth (ESM 1 Fig. S1 and Table SIV). Group 4 (genera Mandrillus and Papio) had the largest home range and daily travel distance (ESM 1 Table SIV and Fig. S1). To some extent the different groups occupied different ecogeographical regions (Fig. 4), with some mostly living in dense forest, namely groups 1 and 5, and others in more open forest with lower canopies (group 2). Some cover a wide range of environment types (groups 3 and 4).

\section{Species-Level Analyses}

The first two RLQ ordination axes account for $97.82 \%$ of total inertia, with the first axis accounting for most of this (Table V). Both RLQ axes are well correlated with the original site-by-species matrix (Table V). The axes show a similar relationship with biological and environmental traits as the analysis at genus level. Daily travel, age at first birth, interbirth interval, and arborealism are the most important biological traits (Table VI). The most important environmental variables are temperature seasonality, annual precipitation, canopy height, and temperature diurnal range (Table VI). Arboreal and frugivorous species are associated with taller canopies and higher precipitation, while terrestrial, omnivorous, 
Table IV Summary statistics for Monte Carlo significance tests for biological trait-environment relationships at genus level in African haplorrhines using three different permutation models

\begin{tabular}{llll}
\hline Model & Observed value & $\begin{array}{l}\text { Standardized value } \\
\text { of the observation }\end{array}$ & $<$-value \\
\hline $\begin{array}{l}\text { Test the significance of environment (R) independent } \\
\text { of trait variation (Q) }\end{array}$ & 1.80 & 134.37 & $0.01^{*}$ \\
$\begin{array}{c}\text { Test the significance of traits (Q) independent } \\
\text { of environmental variation (R) }\end{array}$ & 1.80 & 0.19 & 0.37 \\
$\begin{array}{c}\text { Combine the first two models to test the null hypothesis } \\
\text { that at least one of R and Q is not linked to L }\end{array}$ & 1.80 & 0.18 & \\
\hline
\end{tabular}

*Denotes significance at $\alpha=0.05$

and wider ranging species are associated with higher temperature seasonality and diurnal range (Fig. 5a, b). The first RLQ ordination axis for the trait variables (Q) is significantly positively associated with annual precipitation and canopy height, and negatively associated with diurnal range, temperature seasonality, and precipitation seasonality (Fig. 5d), while the second axis is positively associated with precipitation seasonality (Fig. 5d). Associations of species traits with the environmental axes are not significant; most of the variation in distributions therefore is explained by environmental factors (Fig. 5c). Combining the fourth corner and RLQ analyses with Monte-Carlo tests confirms that environment was important in determining species' distributions, while traits were not (Table VII).

The fourth-corner analysis shows that daily travel distance is positively correlated with diurnal temperature range, monthly temperature seasonality, and precipitation seasonality; interbirth interval is negatively associated with precipitation seasonality; birth rate is associated with canopy height; and arborealism is associated with temperature diurnal range, temperature seasonality, annual precipitation and precipitation seasonality (before correcting for multiple tests, but not after correction; ESM 1 Table SV).

\section{Species Groups}

We placed species into functional groups according to the outcome of the RLQ analyses using a hierarchical cluster analysis (Fig. 5a) and compared the groups in terms of biological traits. The only difference was that group 5 had a larger daily travel distance than the other groups (ESM 1 Table SVI and Fig. S2). The species' groups appear to cluster by ecoregion (Fig. 6). Groups 1, 5, 6, and 9 (mainly Cercopithecus,

Table V Summary of RLQ results testing relationships between environmental variables and biological traits at species level in African haplorrhines

\begin{tabular}{lllll}
\hline $\begin{array}{l}\text { RLQ } \\
\text { axis }\end{array}$ & Eigenvalues & Covariance & $\begin{array}{l}\text { Contribution to } \\
\text { total inertia (\%) }\end{array}$ & $\begin{array}{l}\text { corrL (correlation between trait-based species scores } \\
\text { and site-based environmental scores) }\end{array}$ \\
\hline 1 & 1.59 & 1.26 & 94.11 & 0.46 \\
2 & 0.06 & 0.25 & 3.71 & 0.30 \\
\hline
\end{tabular}


Table VI Percentage contributions to total inertia and relative contributions (\%) to both RLQ axes of individual trait and environmental variables in analysis of the relationships between environmental variables and biological traits in African haplorrhine species

\begin{tabular}{llll}
\hline Variables & Inertia $(\%)$ & Axis 1 (\%) & Axis 2 (\%) \\
\hline Biological trait variables & & & \\
Arboreal & 12.09 & 12.79 & 0.63 \\
Terrestrial & 9.60 & 10.16 & 0.50 \\
Frugivorous & 8.30 & 8.14 & 3.23 \\
Omnivorous & 2.87 & 3.01 & 0.97 \\
Folivorous & 3.23 & 3.08 & 0.77 \\
Intermembral index & 2.50 & 2.33 & 3.98 \\
Body mass & 0.26 & 0.08 & 0.57 \\
Group size & 8.43 & 8.47 & 9.53 \\
Age at first birth & 15.82 & 16.47 & 4.26 \\
Sexual dimorphism & 1.85 & 1.39 & 5.34 \\
Interbirth interval & 12.30 & 10.66 & 58.18 \\
Home range size & 4.92 & 4.67 & 4.67 \\
Daily travel & 17.83 & 18.77 & 2.19 \\
Environmental variables & & & \\
Mean annual temperature & 1.97 & 0.25 & 43.13 \\
Temperature diurnal range & 16.21 & 17.07 & 0.16 \\
Temperature seasonality & 32.54 & 33.46 & 6.04 \\
Annual precipitation & 17.91 & 18.53 & 4.65 \\
Precipitation seasonality & 15.13 & 14.15 & 45.41 \\
Canopy height & 16.25 & 16.53 & 0.60 \\
\hline
\end{tabular}

Pan, Gorilla, and Colobus spp.) are found predominantly in dense forest, while groups 2 and 4 (Theropithecus, Miopithecus, and Chlorocebus spp.) are in more open environments, and groups 3, 7, and 8 (Mandrillus, Papio, Erythrocebus, and Cercocebus spp.) are spread across a variety of habitats.

Table VII Summary statistics for Monte Carlo test for significance of trait-environment relationships at species level in African haplorrhines using three different permutation models

\begin{tabular}{llll}
\hline Model & Observed value & $\begin{array}{l}\text { Standardised value } \\
\text { of the observation }\end{array}$ & $P$-value \\
\hline $\begin{array}{l}\text { Test the significance of environment (R) } \\
\text { independent of trait variation (Q) }\end{array}$ & 1.69 & 139.38 & $<0.01^{*}$ \\
$\begin{array}{l}\text { Test the significance of traits (Q) independent } \\
\text { of environmental variation (R) }\end{array}$ & 1.69 & 1.37 & 0.09 \\
$\begin{array}{l}\text { Combine the first two models to test the null hypothesis } \\
\text { that at least one of R and Q is not linked to L }\end{array}$ & 1.69 & 1.34 & 0.09 \\
\hline
\end{tabular}

*Denotes significance at $\alpha=0.05$. 


\section{Discussion}

Theoretically, biological traits are expected to greatly influence distribution patterns, and specific genera or species' biological traits are hypothesized to be associated with specific environmental conditions. Within the haplorrhines in Africa, we did not find any significant associations between groups of traits and groups of environmental variables, nor did particular groups of traits associate significantly with distribution patterns. We did confirm that environmental conditions at sites explain which species are found at those sites: there was a clear association between environmental conditions and species' distributions. This means our analyses show that environmental filtering is important but that none of the traits that we predicted to be associated with particular environmental conditions could explain why specific species associated with specific environmental conditions. Species and genera could be grouped according to their environmental preferences but those preferences were not associated with specific traits. These results support Beaudrot and Marshal (2019), who showed environmental filtering influenced community composition in African primates at the genus level, but our analyses also found the effect at species level, which Beaudrot and Marshal (2019) did not observe.

Our analysis showed that environmental filtering is important in shaping primate distributions, consistent with the continental scale results of Kamilar (2009). Axis 1 of the environment-distribution analysis was responsible for almost all variation in distribution patterns. The strongest individual environmental drivers were temperature seasonality, annual precipitation, and canopy height. The right-hand side of axis 1 represents environments with higher precipitation and taller canopies (i.e., dense productive forest), and the left-hand side represents environments with high temperature seasonality and greater diurnal temperature range (i.e., open woodland/savannah). All of these variables have been found to be important in previous studies of primate species' distributions (Gouveia et al. 2014; Kamilar et al. 2015; Korstjens et al. 2010), along with other environmental factors that may influence trait distributions such as altitude, canopy cover, and indirect factors such as soil nutrients (Beaudrot and Marshall 2019; Laughlin et al. 2011) that were not tested here. Although the relationships suggested here were directional, environmental variables may not have a linear relationship with species tolerances: e.g., increasing temperature is likely to be a positive influence on primate presence up to a point, but most species will not tolerate very high temperatures. Therefore, measures of environmental harshness, which correlate with phylogenetic structuring in mammals, may be important (Kamilar et al. 2014). The analyses conducted here also provided support for clustering by ecoregion (Fleagle and Reed 1996; Muldoon and Goodman 2010).

The finding that biological traits do not appear to affect species distributions in African primates is somewhat surprising given that we expected that environmentspecies relationships would be driven by biological traits. The traits that contributed most to variation in genus distributions were life history traits (34.48\% of the variation), while only $16.87 \%$ and $18.67 \%$ of variation was explained by substrate used (terrestrial/arboreal) and diet respectively. At species level, $28.12 \%$ of variation in distributions was explained by life history variables and $21.69 \%$ and $14.40 \%$ by substrate use and diet respectively. None of these relationships remained significant when corrected for multiple testing, and combining the analysis of fourth corner and RLQ showed that 


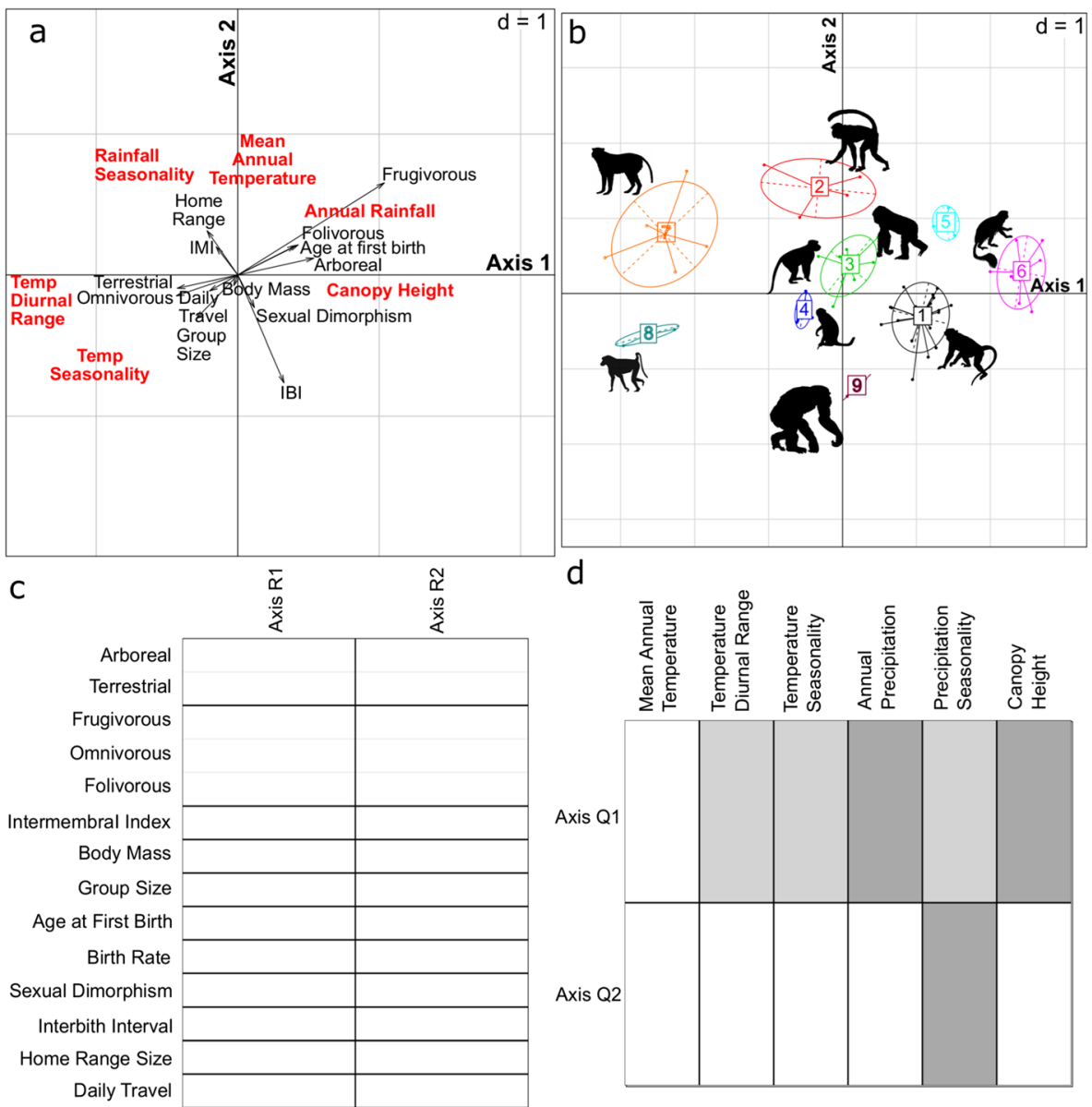

Fig. 5 Results of RLQ and fourth-corner analyses testing relationships between environmental variables and biological traits at species level in African haplorrhines. a Coefficients for trait and environmental variables in RLQ analysis. b Scores for species in RLQ analysis. Colored ellipses indicate clusters of ecologically similar species identified in the analysis as shown in Fig. 6 and ESM 1 Table SVI. c Fourth-corner tests of association between the first two RLQ axes for environmental gradients (AxisR1 and AxisR2) and individual trait variables. d Fourth-corner tests of associations between the first two RLQ axes for trait gradients (Axis Q1 and Axis Q2) and individual environmental variables. In $\mathbf{c}$ and $\mathbf{d}$, light grey cells represent significant negative associations, and white cells represent no significant association (there were no significant positive associations).

the influence of traits on distribution patterns was not significant when environmental conditions were kept constant. The lack of clear relationships between environmental conditions and biological traits and the insignificant role of traits in driving distribution patterns was unexpected considering how important environment has been shown to be in determining the distributions of the plants primates use for both food and substrate (Laughlin et al. 2011).

If primate species specialised on particular food plants, we would expect a strong association between diet and environment, as different environments are likely to contain different food species. However, primates tend to exploit a wide variety of 

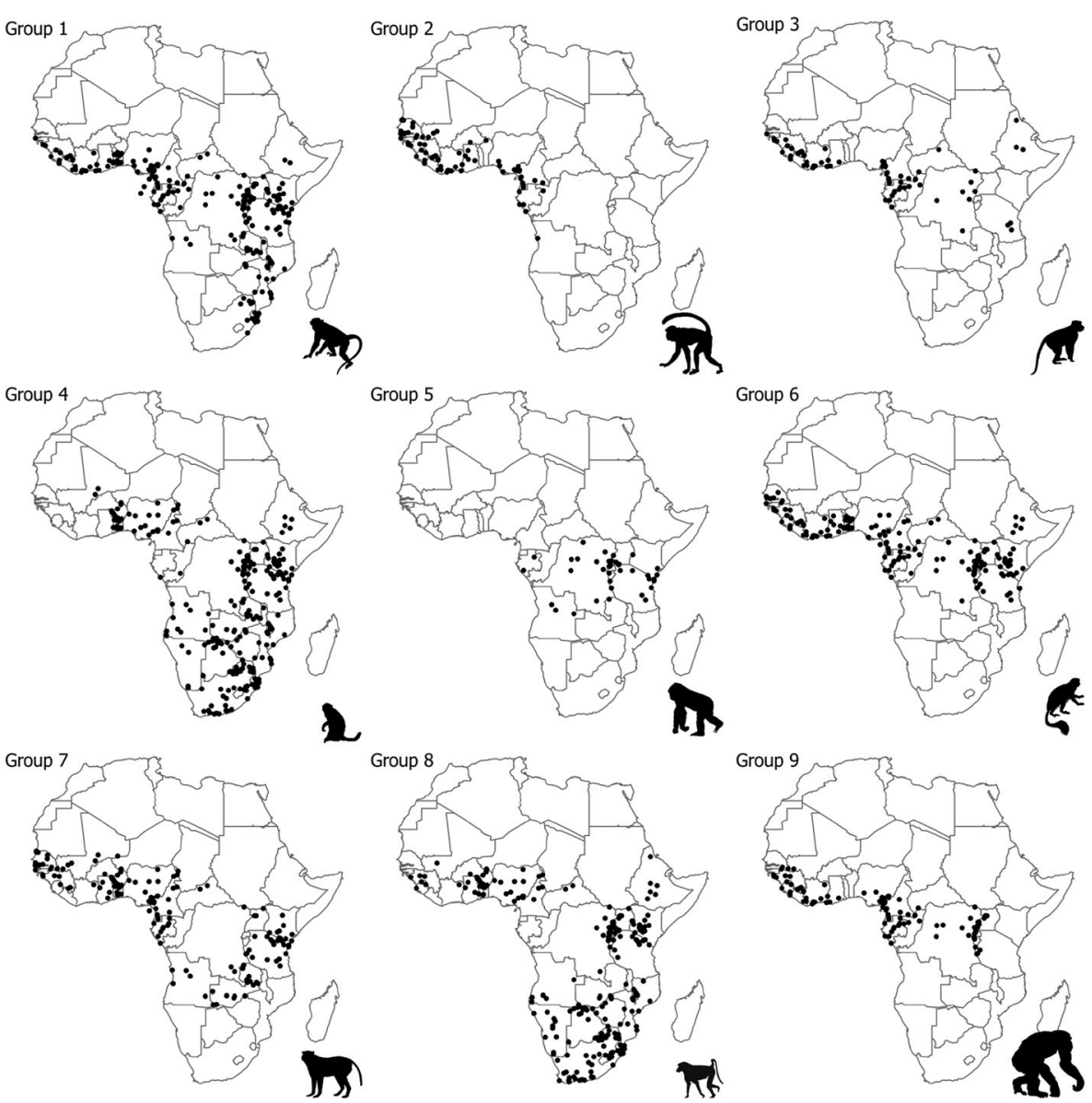

Fig. 6 Maps to show distributions (location where they are present) of each group of ecologically similar species based on trait scores from an RLQ analysis of relationships between environmental variables and biological traits in African haplorrhines (group membership is given in ESM 1 Table SVI).

food sources and many vary their diets significantly according to resource availability (e.g., Cercopithecus mitis: Coleman and Hill 2015). Many genera, including Cercopithecus and Pan, also alter their time budgets, activity levels, group size, and home range in different locations (Campera et al. 2014; Fan et al. 2013; Kalan et al. 2020; Korstjens et al. 2018; Zhou et al. 2013). As these biological traits are not necessarily fixed in primates, the relationship between diet and environmental factors may be less clear than in other taxa in which biological trait filtering has been shown to be important, such as birds and butterflies (Hanspach et al. 2015; Wittmann et al. 2016). Similarly, in Ugandan primate communities, taxonomic similarity within communities was not associated with tree community composition, which was attributed to the fact that primates are generalists (Beaudrot et al. 2013). In addition, most African primates share very similar niche space, with the exception of the Galagidae family (Fleagle and Reed 1996). This, combined with intraspecific variation of traits, means primate communities are likely made up of an essentially random selection of 
ecologically similar species rather than highly specialised species (Beaudrot and Marshall 2011; Rosindell et al. 2011). Similar results have also been found for a wider range of African mammals, where mechanistic models incorporating climate could not predict cooccurrence of different species across their entire ranges (Buschke et al. 2015). Even though primate species are highly adaptable, they are not identical and they do have limitations. In genera Gorilla and Pan, different behavioral patterns and climatic changes affect time budgets, with some behavioral strategies allowing species to better adapt to environmental changes than others (Lehmann et al. 2008). While a species may be able to persist temporarily using a different foraging strategy, they may not be able to do so in the long term (Lehmann et al. 2010). There is also little known about the long-term impacts of lower diet quality on primates: while some species may be able to feed on low-quality food items when resources are scarce, it is not known if they will be able to continue doing so indefinitely (Chapman et al. 2015). The behavioral flexibility of primate species makes it difficult to determine which species will be worst affected by environmental change, highlighting the importance for further research into their adaptability.

None of the analyses we performed here included measures of human pressures, which are likely to be important in determining a species' ability to persist at a given location. Human pressures, including population growth, density, distance to major cities, and the Human Influence Index (a composite measure of human impacts on the environment, taking into account population density, land use, infrastructure, and human access), along with climatic variables, have been shown to be better predictors of mammalian species' ranges than biological traits (Di Marco and Santini 2015). Future models of primate species ranges should take the effect of human pressures into account as well as environmental and biological traits.

The RLQ and fourth-corner methods are well established in ecological studies but have some issues. The patterns identified by RLQ analyses may be changed significantly or even reversed by altering the traits included in the analysis (Calba et al. 2014), so it is important to carry out further research using other approaches. Another significant problem in studies of this type is the effect of scale dependence. For example, in African mammals, mechanistic models containing environmental gradients can explain co-occurrence of different species at local scale but not range-wide scale, which was better explained using biogeographical regions (Buscke et al. 2015). It may be informative to perform the same tests used here on a more local scale, such as within ecoregions, and to develop models based on the current ranges and factors such as dispersal limitations and human pressure. Farneda et al. (2015) used the RLQ-fourthcorner method, along with phylogenetic least square models (PGLS), on communities of Amazonian bats, and found a relationship between functional traits and sensitivity to habitat fragmentation; it would be useful to test this relationship for primates as well. Models using mechanistic environment-trait relationships are more robust (Lavorel and Garnier 2002), as they include less stochasticity and can be more readily used in a species-specific way (Rosindell et al. 2011); however, given the flexibility and diversity of primates shown here, it is likely not possible to produce a general model for primates as a whole. A combination of the analyses used here with other statistical approaches that incorporate human pressures will help to create predictive models that can be used to anticipate species' responses to environmental change and inform conservation policy. 


\section{Conclusions}

We aimed to identify whether there are groups of environmental conditions that favor particular groups of traits in primates, leading to distribution patterns according to their biological traits. Despite using a large number of sites across a broad geographical scale, we did not find any significant associations, suggesting that the environmental conditions and traits investigated do not interact. Primate species distributions are limited by habitat preference, but which biological traits drive their habitat preferences remains unresolved. This makes it difficult, if not impossible, to produce the types of mechanistic predictive models that would be useful for conservation aims.

Supplementary Information The online version contains supplementary material available at https://doi.org/ 10.1007/s10764-021-00208-4.

Acknowledgments We would like to thank Lydia Beaudrot and another anonymous reviewer and the tireless editor Jo Setchell for their helpful feedback on earlier versions of this manuscript. We thank Julia Lehmann, Robin Dunbar, and Marusha Dekleva for their considerable contributions to establishing the data set of primate distributions. A. H. Korstjens was funded by a Leverhulme grant (to R. A. Hill, R. I. M. Dunbar, and S. Elton, F/00128/T) when she started the development of the species distribution data set at Liverpool University. We thank Bournemouth University Departmental QR funds for funding HDS and M. Dekleva. The work presented is part of the LEAP: Landscape Ecology and Primatology program (go-leap.wixsite.com/ home).

Author Contributions KAW and AHK conceived and designed the study. KAW and HDS collected data and KAW, HDS, and PG performed the analysis. KAW and HDS wrote the manuscript; other authors provided editorial advice.

Open Access This article is licensed under a Creative Commons Attribution 4.0 International License, which permits use, sharing, adaptation, distribution and reproduction in any medium or format, as long as you give appropriate credit to the original author(s) and the source, provide a link to the Creative Commons licence, and indicate if changes were made. The images or other third party material in this article are included in the article's Creative Commons licence, unless indicated otherwise in a credit line to the material. If material is not included in the article's Creative Commons licence and your intended use is not permitted by statutory regulation or exceeds the permitted use, you will need to obtain permission directly from the copyright holder. To view a copy of this licence, visit http://creativecommons.org/licenses/by/4.0/.

\section{References}

Abernethy, K. A., White, L. J. T., \& Wickings, E. J. (2002). Hordes of mandrills (Mandrillus sphinx): Extreme group size and seasonal male presence. Journal of Zoology, 258(1), 131-137. https://doi.org/10.1017/ s0952836902001267.

Bannar-Martin, K. H. (2014). Primate and nonprimate mammal community assembly: The influence of biogeographic barriers and spatial scale. International Journal of Primatology, 35(6), 1122-1142. https://doi.org/10.1007/s10764-014-9792-2.

Beaudrot, L. H., \& Marshall, A. J. (2011). Primate communities are structured more by dispersal limitation than by niches. Journal of Animal Ecology, 80(2), 332-341. https://doi.org/10.1111/j.1365-2656.2010. 01777.x.

Beaudrot, L., Rejmánek, M., \& Marshall, A. J. (2013). Dispersal modes affect tropical forest assembly across trophic levels. Ecography, 36(9), 984-993. https://doi.org/10.1111/j.1600-0587.2013.00122.x. 
Beaudrot, L., \& Marshall, A. J. (2019). Differences among regions in environmental predictors of primate community similarity affect conclusions about community assembly. Journal of Tropical Ecology, 35(2), 83-90. https://doi.org/10.1017/S0266467418000470.

Buschke, F. T., De Meester, L., Brendonck, L., \& Vanschoenwinkel, B. (2015). Partitioning the variation in African vertebrate distributions into environmental and spatial components - exploring the link between ecology and biogeography. Ecography, 38(5), 450-461. https://doi.org/10.1111/ecog.00860.

Buscke, F. T., Brendonck, L., \& Vanschoenwinkel, B. (2015). Simple mechanistic models can partially explain local but not range-wide co-occurrence of African mammals. Global Ecology and Biogeography, 24, 762-773. https://doi.org/10.1111/geb.12316.

Cadotte, M., \& Tucker, C. M. (2017). Should environmental filtering be abandoned? Trends in Ecology and Evolution, 32(6), 429-437. https://doi.org/10.1016/j.tree.2017.03.004.

Calba, S., Maris, V., \& Devictor, V. (2014). Measuring and explaining large-scale distribution of functional and phylogenetic diversity in birds: Separating ecological drivers from methodological choices. Global Ecology and Biogeography, 23(6), 669-678. https://oi.org/10.1111/geb.12148.

Campbell, C., Fuentes, A., MacKinnon, K., Panger, M., \& Bearder, S. K. (2007). Primates in perspective (1st ed.). Oxford University Press.

Campera, M., Serra, V., Balestri, M., Barresi, M., Ravaolahy, M., et al (2014). Effects of habitat quality and seasonality on ranging patterns of collared brown lemur (Eulemur collaris) in littoral forest fragments. International Journal of Primatology, 35(5), 957-975. https://oi.org/10.1007/s10764-014-9780-6.

Cardillo, M. (2011). Phylogenetic structure of mammal assemblages at large geographical scales: Linking phylogenetic community ecology with macroecology. Philosophical Transactions of the Royal Society Of London B: Biological Sciences, 366, 2545-2553. https://doi.org/10.1098/rstb.2011.0021.

Chapman, C. A., Schoof, A. M., Bonnell, T. R., Gogarten, J. F., \& Calme, S. (2015). Competing pressures on populations : Long-term dynamics of food availability, food quality, disease, stress and animal abundance. Philosophical Transactions of the Royal Society of London B: Biological Sciences, 370. https://doi. org/10.1098/rstb.2014.0112.

Coleman, B. T., \& Hill, R. A. (2015). Biogeographic variation in the diet and behaviour of Cercopithecis mitis. Folia Primatologica, 85, 319-334. https://doi.org/10.1159/000368895.

Connolly, S. R., Keith, S. A., Colwell, R. K., \& Rahbek, C. (2017). Process, mechanism, and modeling in macroecology. Trends in Ecology \& Evolution, 32(11), 835-844. https://doi.org/10.1016/j.tree.2017.08. 011.

Davidson, A. D., Shoemaker, K. T., Weinstein, B., Costa, G. C., Brooks, T. M., et al (2017). Geography of current and future global mammal extinction risk. PloS ONE, 12(11). https://doi.org/10.1371/journal. pone. 0186934 .

Di Marco, M., \& Santini, L. (2015). Human pressures predict species ' geographic range size better than biological traits. Global Change Biology, 21, 2169-2178. https://doi.org/10.1111/gcb.12834.

Dray, S., Choler, P., Doledec, S., Peres-Neto, P. R., Thuiller, W., et al (2014). Combining the fourth-corner and the RLQ methods for assessing trait responses to environmental variation. Ecology, 95(1), 14-21. https://doi.org/10.1890/13-0196.1.

Dray, S., \& Dufour, A. (2007). The ade4 package: Implementing the duality diagram for ecologists. Journal of Statistical Software, 22(4), 1-20. https://doi.org/10.18637/jss.v022.i04.

Dunbar, R. I. M., Korstjens, A. H., \& Lehmann, J. (2009). Time as an ecological constraint. Biological Reviews, 84, 413-429. https://doi.org/10.1016/j.anbehav.2009.11.012.

Fan, P., Scott, M. B., Fei, H., \& Ma, C. (2013). Locomotion behavior of cao vit gibbon (Nomascus nasutus) living in karst forest in Bangliang Nature Reserve, Guangxi, China. Integrative Zoology, 8, 356-364. https://doi.org/10.1111/j.1749-4877.2012.00300.x.

Farneda, Z., Rocha, R., Palmeirim, J. M., Bobrowiec, P. E. D., \& Meyer, C. F. J. (2015). Trait-related responses to habitat fragmentation in Amazonian bats. Journal of Applied Ecology, 52, 1381-1391. https://doi.org/10.1111/1365-2664.12490.

Fleagle, J. G., \& Reed, K. E. (1996). Comparing primate communities: A multivariate approach. Journal of Human Evolution, 30(6), 489-510. https://doi.org/10.1006/jhev.1996.0039.

Gaston, K. J. (2000). Global patterns in biodiversity. Nature, 405, 220-227. https://doi.org/10.1038/ 35012228.

Gouveia, S. F., Villalobos, F., Dobrovolski, R., Beltrão-Mendes, R., \& Ferrari, S. F. (2014). Forest structure drives global diversity of primates. The Journal of Animal Ecology [online]. Available from: http://www. ncbi.nlm.nih.gov/pubmed/24773500. Accessed 21 October 2014. https://doi.org/10.1111/1365-2656. 12241. 
Graham, T. L., Matthews, H. D., \& Turner, S. E. (2016). A global-scale evaluation of primate exposure and vulnerability to climate change. International Journal of Primatology. https://doi.org/10.1007/s10764016-9890-4.

Guschanski, K., Krause, J., Sawyer, S., Valente, L. M., Bailey, S., et al (2013). Next-generation museomics disentangles one of the largest primate radiations. Systematic Biology, 62(4), 539-554. https://doi.org/10. 1093/sysbio/syt018.

Hanspach, J., Loos, J., Dorresteijn, I., Von Wehrden, H., Moga, C. I., \& David, A. (2015). Functional diversity and trait composition of butterfly and bird communities in farmlands of Central Romania. Ecosystem Health and Sustainability, 1(9), 32. https://doi.org/10.1890/ehs15-0027.1.

Hidasi-Neto, J., Barlow, J., \& Cianciaruso, M. V. (2012). Bird functional diversity and wildfires in the Amazon: The role of forest structure. Animal Conservation, 15, 407-415. https://doi.org/10.1111/j.14691795.2012.00528.x.

Hidasi-Neto, J., Bini, L. M., Siqueira, T., \& Cianciaruso, M. V. (2020). Ecological similarity explains species abundance distribution of small mammal communities. Acta Oecologica, 102. https://doi.org/10.1016/j. actao.2019.103502.

Hijmans, R. J., Cameron, S., \& Parra, J. (2015). WorldClim [online]. Berkley, University of California. Available from: http://worldclim.org/.

Hurlbert, A. H., \& Jetz, W. (2007). Species richness, hotspots and the scale dependence of range maps in ecology and conservation. PNAS, 104(33), 13384-13389. https://doi.org/10.1073/pnas.0704469104.

Isbell, L. A., \& Van Vuren, D. (1995). Differential costs of locational and social dispersal and their consequences for female group-living primates. Behaviour, 133, 1-36. https://doi.org/10.1163/ $156853996 x 00017$.

Jungers W. L. (1985). Body size and scaling of limb proportions in primates. In W. L. Jungers (Ed.), Size and scaling in primate biology. Advances in Primatology. Springer. https://doi.org/10.1007/978-1-48993647-9 16.

Kalan, A. K., Kulik, L., Arandjelovic, M., Boesch, C., Haas, F., et al (2020). Environmental variability supports chimpanzee behavioural diversity. Nature Communications, 11(1), 1-10. https://doi.org/10. 1038/s41467-020-18176-3.

Kamilar, J. M. (2009). Environmental and geographic correlates of the taxonomic structure of primate communities. American Journal of Physical Anthropology, 139(3), 382-393. https://doi.org/10.1002/ ajpa.20993.

Kamilar, J. M., \& Beaudrot, L. (2013). Understanding primate communities: Recent developments and future directions. Evolutionary Anthropology, 22, 174-185. https://doi.org/10.1002/evan.21361.

Kamilar, J. M., Beaudrot, L. H., \& Reed, K. E. (2014). The influences of species richness and climate on the phylogenetic structure of African Haplorhine and Strepsirhine primate communities. International Journal of Primatology, 35(6), 1105-1121. https://doi.org/10.1007/s10764-014-9784-2.

Kamilar, J. M., Beaudrot, L. H., \& Reed, K. E. (2015). Climate and species richness predict the phylogenetic structuring of African mammal communities. PloS ONE, 10(4). https://doi.org/10.1371/journal.pone. 0121808 .

Kay, R. F., Madden, R. H., Van Schaik, C., \& Higdon, D. (1997). Primate species richness is determined by plant productivity. Proceedings of the National Academy of Sciences of the USA, 94(24). https://doi.org/ 10.1073/pnas.94.24.13023.

Kingdon, J., \& Groves, C. P. (2013). Tribe Cercopithecini. In T. M. Butynski, J. Kingdon, \& J. Kalina (Eds.), Mammals of Africa, Primates (Vol. II, pp. 245-247). Bloomsbury.

Kingdon, J., Happold, D., Butynski, T., Hoffmann, M., Happold, M., \& Kalina, J. (2013). Mammals of Africa, Vol, II: Primates, 1st ed. Bloomsbury.

Korstjens, A. H. (2019). The effect of climate change on the distribution of the genera colobus and cercopithecus. In A. M. Behie, J. A. Teichroeb, \& N. Malone (Eds.), Primate research and conservation in the Anthropocene (Cambridge studies in biological and evolutionary anthropology) (pp. 257-280). Cambridge: Cambridge University Press. https://doi.org/10.1017/9781316662021.015.

Korstjens, A. H., \& Hillyer, A. P. (2016). Primates and climate change: A review of current knowledge. In S. A. Wich \& A. J. Marshall (Eds.), An introduction to primate conservation (pp. 175-192). Oxford University Press. https://doi.org/10.1093/acprof:oso/9780198703389.003.0011.

Korstjens, A. H., Lehmann, J., \& Dunbar, R. I. M. (2010). Resting time as an ecological constraint on primate biogeography. Animal Behaviour, 79(2), 361-374. https://doi.org/10.1016/j.anbehav.2009.11.012.

Korstjens, A. H., Lehmann, J., \& Dunbar, R. I. M. (2018). Time constraints do not limit group size in arboreal guenons but do explain community size and distribution patterns. International Journal of Primatology, 39(4), 511-531. https://doi.org/10.1007/s10764-018-0048-4. 
Lahm, S. (1986). Diet and habitat preference of Mandrillus sphinx in Gabon: Implications of foraging strategy. American Journal of Primatology, 11(1), 9-26. https://doi.org/10.1002/ajp.1350110103.

Laughlin, D. C., Fule, P. Z., Huffman, D. W., Crouse, J., \& Laliberte, E. (2011). Climatic constraints on traitbased forest assembly. Journal of Ecology, 99(6), 1489-1499. https://doi.org/10.1111/j.1365-2745.2011. 01885.x.

Lavorel, S., \& Garnier, E. (2002). Predicting changes in community composition and ecosystem functioning from plant traits: Revisiting the holy grail. Functional Ecology, 16(5), 545-556. https://doi.org/10.1046/j. 1365-2435.2002.00664.x.

Lehmann, J., Korstjens, A. H., \& Dunbar, R. I. M. (2008). Time and distribution: A model of ape biogeography. Ethology Ecology \& Evolution, 20, 337-359. https://doi.org/10.1080/08927014.2008. 9522516.

Lehmann, J., Korstjens, A. H., \& Dunbar, R. I. M. (2010). Apes in a changing world: The effects of global warming on the behaviour and distribution of African apes. Journal of Biogeography, 37(12), 22172231. https://doi.org/10.1111/j.1365-2699.2010.02373.x.

Losos, J. B. (2008). Phylogenetic niche conservatism, phylogenetic signal and the relationship between phylogenetic relatedness and ecological similarity among species. Ecology Letters, 11(10), 995-1003. https://doi.org/10.1111/j.1461-0248.2008.01229.x.

Mayfield, M. M., \& Levine, J. M. (2010). Opposing effects of competitive exclusion on the phylogenetic structure of communities. Ecology Letters, 13, 1085-1093. https://doi.org/10.1111/J.1461-0248.2010. 01509.X.

Mazel, F., Renaud, J., Guilhaumon, F., Mouillot, D., Gravel, D., \& Thuiller, W. (2015). Mammalian phylogenetic diversity-area relationships at a continental scale. Ecology, 96(10), 2814-2822. https://doi. org/10.1890/14-1858.1.

Muldoon, K. M., \& Goodman, S. M. (2010). Ecological biogeography of Malagasy non-volant mammals: Community structure is correlated with habitat. Journal of Biogeography, 37(6), 1144-1159. https://doi. org/10.1111/j.1365-2699.2010.02276.x.

Pavoine, S., Vela, E., Gachet, S., De Bélair, G., \& Bonsall, M. B. (2011). Linking patterns in phylogeny, traits, abiotic variables and space: A novel approach to linking environmental filtering and plant community assembly. Journal of Ecology, 99, 165-175. https://doi.org/10.1111/j.1365-2745.2010.01743.x.

Razafindratsima, O. H., Mehtani, S., \& Dunham, A. E. (2012). Extinctions, traits and phylogenetic community structure: Insights from primate assemblages in Madagascar. Ecography, 36(1), 47-56. https://doi.org/10. 1111/j.1600-0587.2011.07409.x.

Richmond, B. G., Aiello, L. C., \& Wood, B. A. (2002). Early hominin limb proportions. Journal of Human Evolution, 43(4), 529-548. https://doi.org/10.1006/jhev.2002.0594.

Ricklefs, R. E. (2015). Intrinsic dynamics of the regional community. Ecology Letters, 18, 497-503. https:// doi.org/10.1111/ele.12431.

Rosindell, J., Hubbell, S. P., \& Etienne, R. S. (2011). The unified neutral theory of biodiversity and biogeography at age ten. Trends in Ecology \& Evolution, 26(7), 340-348. https://doi.org/10.1016/j.tree. 2011.03.024.

Rowan, J., Beaudrot, L., Franklin, J., Reed, K. E., Smail, I. E., et al (2020). Geographically divergent evolutionary and ecological legacies shape mammal biodiversity in the global tropics and subtropics. Proceedings of the National Academy of Sciences of the USA, 117(3), 1559-1565.

Rowan, J., Kamilar, J. M., Beaudrot, L., \& Reed, K. E. (2016). Strong influence of palaeoclimate on the structure of modern African mammal communities. Proceedings of the Royal Society of London B: Biological Sciences, 283(1840), 20161207. https://doi.org/10.1098/rspb.2016.1207.

R Core Team. (2016). R: A language and environment for statistical computing. In $R$ Foundation for statistical computing. Vienna: Austria https://www.R-project.org/.

Santini, L., Cornulier, T., Bullock, J. M., Palmer, S. C. F., White, S. M., et al (2016). A trait-based approach for predicting species responses to environmental change from sparse data: How well might terrestrial mammals track climate change? Global Change Biology, 22(7), 2415-2424. https://doi.org/10.1111/gcb. 13271.

Simard, M., Pinto, N., Fisher, J. B., \& Baccini, A. (2011). Mapping forest canopy height globally with spaceborne lidar. Journal of Geophysical Research: Biogeosciences, 32(6), 523-559. https://doi.org/10. 1029/2011jg001708.

Smith, R. J., \& Jungers, W. L. (1997). Body mass in comparative primatology. Journal of Human Evolution, 32(6), 523-559. https://doi.org/10.1006/jhev.1996.0122.

Stewart, B. M., Turner, S. E., \& Matthews, H. D. (2020). Climate change impacts on potential future ranges of non-human primate species. Climatic Change, 162, 2301-2318. https://doi.org/10.1007/s10584-02002776-5. 
Wang, Y. C., Srivathsan, A., Feng, C. C., Salim, A., \& Shekelle, M. (2013). Asian primate species richness correlates with rainfall. PloS ONE, 8(1). https://doi.org/10.1371/journal.pone.0054995.

Willems, E. P., Hellriegel, B., \& Van Schaik, C. P. (2013). The collective action problem in primate territory economics. Proceedings of the Royal Society of London B: Biological Sciences, 280. https://doi.org/10. 1098/rspb.2013.0081.

Wittmann, M. E., Barnes, M. A., Jerde, C. L., Jones, L. A., \& Lodge, D. M. (2016). Confronting species distribution model predictions with species functional traits. Ecology and Evolution, 6(4), 873-879. https://doi.org/10.1002/ece3.1898.

Zhang, L., Ameca, E. I., Cowlishaw, G., Pettorelli, N., Foden, W., \& Mace, G. M. (2019). Global assessment of primate vulnerability to extreme climatic events. Nature Climate Change, 9, 554-561. https://doi.org/ 10.1016/b978-0-12-384703-4.00409-3.

Zhou, Q., Luo, B., Wei, F., \& Huang, C. (2013). Habitat use and locomotion of the François' langur (Trachypithecus francoisi) in limestone habitats of Nonggang, China. Integrative Zoology, 8, 346-355. https://doi.org/10.1111/j.1749-4877.2012.00299.x.

\section{Affiliations}

\section{Katherine A. Williams ${ }^{1,3}$ - Helen D. Slater ${ }^{2,3}$ • Phillipa Gillingham ${ }^{2,3}$ • Amanda H. Korstjens ${ }^{2,3}$}

Amanda H. Korstjens

akorstjens@bournemouth.ac.uk

1 Bioengineering Research Group, Faculty of Engineering and Physical Sciences, University of Southampton, Southampton, UK

2 Department of Life and Environmental Sciences, Bournemouth University, Poole, Dorset, UK

3 Landscape Ecology and Primatology (LEAP), Bournemouth University, Poole, Dorset, UK 